\title{
Universal Access to Health and Universal Health Coverage: identification of nursing research priorities in Latin America
}

\author{
Silvia Helena De Bortoli Cassiani \\ Alessandra Bassalobre-Garcia ${ }^{2}$ \\ Ludovic Reveiz $^{3}$
}

Objective: To estabilish a regional list for nursing research priorities in health systems and services in the Region of the Americas based on the concepts of Universal Access to Health and Universal Health Coverage. Method: five-stage consensus process: systematic review of literature; appraisal of resulting questions and topics; ranking of the items by graduate program coordinators; discussion and ranking amongst a forum of researchers and public health leaders; and consultation with the Ministries of Health of the Pan American Health Organization's member states. Results: the resulting list of nursing research priorities consists of 276 study questions/ topics, which are sorted into 14 subcategories distributed into six major categories: 1 . Policies and education of nursing human resources; 2 . Structure, organization and dynamics of health systems and services; 3. Science, technology, innovation, and information systems in public health; 4. Financing of health systems and services; 5 . Health policies, governance, and social control; and 6. Social studies in the health field. Conclusion: the list of nursing research priorities is expected to serve as guidance and support for nursing research on health systems and services across Latin America. Not only researchers, but also Ministries of Health, leaders in public health, and research funding agencies are encouraged to use the results of this list to help inform research-funding decisions.

Descriptors: Nursing; Research; Nursing Research; Health Services Research; Consensus; Americas.

\footnotetext{
${ }^{1}$ PhD, RN, Advisor on Nursing and Allied Health Personnel, Health Systems and Services Department, Pan American Health Organization, Washington, DC, USA.

${ }^{2}$ BSN, MSc, Intern (2014), Health Systems and Services Department, Pan American Health Organization, Washington, DC, USA.

${ }^{3}$ Advisor, Knowledge Management, Bioethics and Research Department, Pan American Health Organization, Washington, DC, USA.
}

Corresponding Author:

Silvia Helena De Bortoli Cassiani

Pan American Health Organization. Health Systems and Services Department

525 Twenty Third Street NW 20037 Washington DC, USA

E-mail: cassianis@paho.org
Copyright (๑) 2015 Revista Latino-Americana de Enfermagem This is an Open Access article distributed under the terms of the Creative Commons Attribution Non-Commercial License (CC BY-NC).

This license lets others distribute, remix, tweak, and build upon your work non-commercially, and although their new works must also acknowledge you and be non-commercial, they don't have to license their derivative works on the same terms. 


\section{Introduction}

In October 2014, the Pan American Health Organization/World Health Organization (PAHO/WHO) and its Member States adopted the Resolution CD53/5, Rev. 2 - Strategy for Universal Access to Health and Universal Health Coverage (Universal Health), which first defines this as the absence of sociocultural, organizational, economic, geographical, and genderrelated barriers to healthcare, and second, as the capacity of health systems to meet the needs of populations at any level of care, providing infrastructure, adequate human resource capacity, and health technologies without causing financial harm(1).

These two concepts of Universal Health hold paramount importance for the improvement of health outcomes and to reach other significant health system objectives. These are based on the basic human right to be able to enjoy a healthy life. The Universal Health strategy also represents an inclusive umbrella for other issues and stakeholders affected by the health

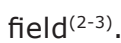

Additionally, Universal Health requires solid health systems supported by motivated health personnel who are equitably distributed and have acquired an appropriate combination of skills, thus resulting in the provision of quality health services based on the population's needs. Nurses play an important role in the context of Universal Health because of their close contact with people and a greater understanding of their needs. Their education should therefore qualify them to produce and apply scientific evidence within their practice, while also fostering critical and reflexive thinking in order to deliver a better quality and community-centered care ${ }^{(4-5)}$.

Beyond technical and scientific qualifications, the ethical and political competencies of nursing are additional dimensions that must be taken into consideration by toward in health systems that are designed to effectively implement health as a basic human right for the achivement of Universal Health(6).

The commitment, collaborative work, exchange of knowledge and experience performed by the 25 international nursing networks in Latin America can be a clear example of the contributions for $\mathrm{UAH}$ and $\mathrm{UHC}^{(5)}$; however, there is still a need to set priorities for the collaborative research.
Nursing sciences continues to increase its scientific output. Differences among nurses remain based on their training, ability to lead research, and implement evidence-based professional practice. Despite this recognized increase in nursing literature, little has been carried out within the context of health systems and services, or conducted by nursing that work in research settings ${ }^{(7-9)}$.

On the other hand, the field of health systems and services research has continued to gain worldwide attention in the last decade ${ }^{(10)}$. This field of research, along with research in social, economic and cultural determinants of health, has been poorly explored in some Latin American countries ${ }^{(11)}$.

For the reasons mentioned above, there is a need to discuss nursing research priorities in order for there to be synergy in addressing health issues, healthcare practices, and major global health challenges, particularly those related to current debates involving health policies.

Furthermore, "developing an adequately financed research agenda, and a better knowledge management are essential elements to address social determinants of health, ensure access to quality services, incorporate technology, and evaluate the effectiveness of implemented actions and programs." (1)

In this context, the objective of this study was to set a list for nursing research priorities on health systems and services in the Americas based on the concepts of Universal Access to Health and Universal Health Coverage.

\section{Method}

This study was carried out through a group consensus method. A group consensus combines a variety of perspectives and information on a specific area in a systematic and organized way. This method involves participation by experts and its objective is to synthesize accumulated expert opinions and knowledge about the area of interest. It also enhances the decisionmaking and policy development process, as well as the identification and measurement of areas where there is uncertainty, controversy or incomplete evidence ${ }^{(12)}$.

In order to reach group consensus, a five-stage process was undertaken (figure 1 ). 


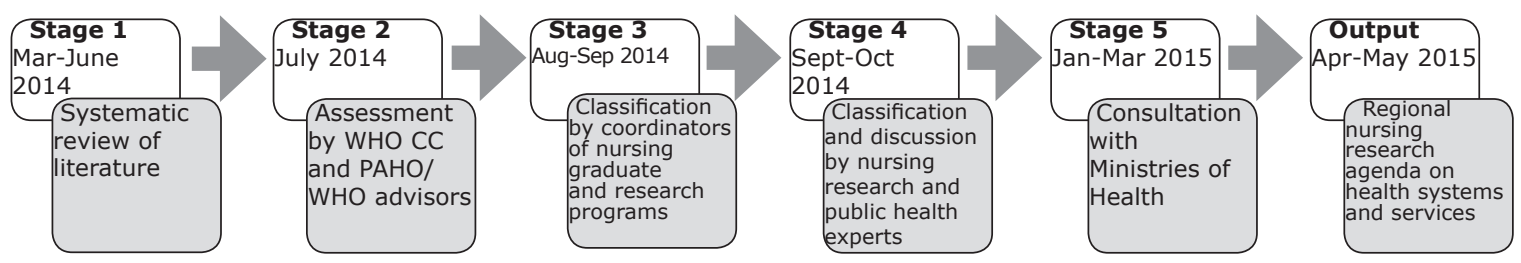

Figure 1 - Group consensus stages to establish the list of nursing research priorities

\section{Stage 1: Systematic review of literature(13)}

The first stage consisted of a systematic review of literature, which was conducted from March to June 2014, and guided by the following study question: "Are there priority nursing research agendas focused on health systems and services or public health?" The databases used for the initial literature search were Web of Science, PubMed, LILACS, and Google (for grey literature). Advanced search strategies were based on Medical Subject Headings (MeSH) and inclusion criteria were documents published between 2008 to 2014 in either English, Spanish, or Portuguese.

Throughout the selection process, three criteria were applied: 1 ) to address nursing research priorities focused on primary health care systems and services or public health; 2) to explicitly formulate research priorities on nursing and/or health systems and services; 3) to relate to the Region of the Americas, or on a global scale that includes the Region. The study questions and topics were compiled and a thematic analysis was conducted to sort them into categories and subcategories.

A previous publication provides details of this systematic review, its search strategies, and assessment of the documents selected ${ }^{(13)}$.

\section{Stage 2: Assessment by WHO Collaborating Centers and PAHO/WHO advisors}

The second stage consisted of an assessment of the questions and topics identified in the review mentioned above. This appraisal was completed by coordinators and professors of the WHO Collaborating Centre for Nursing Research Development at the Ribeirao Preto School of Nursing - University of São Paulo, Brazil, and from the Escuela Nacional de Enfermería y Obstetrícia de la Universidad Autonoma de México; their appraisal was then revised by two PAHO/WHO advisors. This first screening allowed changes to the document and the removal of items deemed as irrelevant.

\section{Stage 3: Classification by coordinators of nursing graduate and research programs}

At the third stage, the topics and questions of the study were submitted to be reviewed and classified by nursing graduate and research program coordinators from across Latin America. In order to retrieve their contacts, a list from Latin American Association of Nursing Schools and Colleges (ALADEFE) was requested; all 81 schools of nursing from ALADEFE's list were requesting the coordinator's contact information.

Next, each coordinator was then requested to complete an evaluation of the document. All items were classified by the coordinators according to a 3-point Likert scale: "high relevance", "relevant", or "low relevance". This classification was based on the criteria: 1) Magnitude and impact - to what extent would the answer of the study question contribute to social welfare and facilitate attaining the objective of Universal Access to Health and Universal Health Coverage; 2) Feasibility - to what extent can the study question be answered in a manner that is based on the concepts of ethical behavior, equity, and sustainable research, while also considering the political, cultural, legal, social, economic, and technological contexts where the research is taking place.

The experts were also encouraged to suggest revisions, remove or propose new research questions/ topics, and make general observations about the agenda. The data was entered into a Microsoft Excel spreadsheet and analyzed by descriptive statistics. The topics and questions with the highest percentage of "low relevance" ratings were removed from the draft agenda.

\section{Stage 4: Ranking and discussion by nursing research and public health experts}

The fourth stage consisted of discussion on the classification of the identified research priorities. This discussion took place during a 2-day meeting held at 
the XV Pan American Nursing Research Colloquium in September 2014 in Cartagena de Indias, Colombia. Coordinators from graduate programs, research programs, deans of nursing schools as well as nurses employed by the ministries of health of 14 Latin American countries were invited to take part in the meeting.

During the first day of the meeting, the motivations that led to the development of the agenda were presented to the attendees, followed by the study methods undertaken, and the state of research in Brazil, Chile and Colombia. Participants were assigned to five groups and were instructed to review and discuss each research topic/question, and classify them as "high relevance", "relevant", or "low relevance" according to the same criteria adopted in stage 3. During the second day of the meeting, participants were asked to finalize their group work and present findings from their small groups, in addition to returning a copy of the agenda containing their ranking and suggested revisions.

Most of the suggestions/modifications were incorporated in the final document, and questions/ topics ranked as "low relevance" were removed from the agenda.

\section{Stage 5: Consultation with Ministries of Health}

The fifth and final stage was a consultation with national authorities in charge of the Human Resources for Health or Nursing units at the Ministries of Health in Latin American and Caribbean countries (PAHO/WHO Member States). Formal solicitations were submitted to the Ministries of Health of 28 countries through each country's $\mathrm{PAHO} / \mathrm{WHO}$ representative office, requesting assessment of the research priorities list, which included changing, adding or removing items according to their expertise of the country's public health, and addressing the concepts of Universal Health. Their suggestions were analyzed and incorporated into the final research list.

\section{Results}

A total of 23 documents were retrieved from the systematic review, and the thematic analysis resulted in a document with 444 research topics/questions distributed into five categories and 16 subcategories ${ }^{(13)}$. This document with compiled topics/questions was the basis for the stages that followed.
In stage 2, all items were assessed and reviewed, and a total of 21 questions/topics were removed from the document.

In stage 3 , of the 81 emails sent to the Schools of Nursing, 31 were answered providing contact information for a total of 92 contacts of nursing graduate and research program coordinators, representing 12 Latin American countries. Nonetheless, only 24 coordinators responded with thorough evaluations and classification of the study topics/questions. As a result, only one question, belonging to the "Policies and education of nursing human resources" category, was removed from the list since it was ranked as being of "low relevance" by $41.7 \%$ of the experts. Additionally, they modified 50 questions/topics, providing suggestions for the inclusion of 16 additional research questions, and 10 general comments on the draft list of priorities. The experts' suggestions were thoroughly reviewed, most of which were accepted.

Stage 4, the 2 day meeting in Colombia was attended by 122 participants representing 12 countries: Argentina, Bolivia, Brazil, Chile, Colombia, Costa Rica, El Salvador, Mexico, Panama, Peru, Portugal and Uruguay. These attendants included nursing researchers, faculty, practitioners, deans, representatives of professional associations, regulatory bodies, Ministries of Health, public health leaders, nursing journal and nursing network coordinators. Their combined work resulted in the removal or modification of 87 topics/questions, an addition of 32 topics, and the inclusion of a sixth category: Social studies in the health field.

During stage 5, formal replies were obtained from the Ministry of Health of eight countries: Belize, Brazil, Colombia, Guatemala, Mexico, Peru, St. Vincent \& the Grenadines, and Uruguay. They suggested adding 30 questions/topics, removing two, and modifying/ rewriting several items within the entire document. All suggestions were reviewed, compared to each other, and added as appropriate.

The entire group consensus process yielded 276 priority research topics/questions sorted into 14 subcategories, which were distributed into six major categories: 1 . Policies and education of nursing human resources; 2. Structure, organization and dynamics of health systems and services; 3. Science, technology, innovation, and information systems in public health; 4. Financing of health systems and services; 5 . Health policies, governance, and social control; and 6. Social studies in the health field (see Figures $2-7$ ). All topics/ questions hold equal priority. 
1. POLICIES AND EDUCATION OF NURSING HUMAN RESOURCES

\subsection{Planning}

Topics

Identification and analysis of national policies/standards for human resources in nursing within the current social, health, demographic, and epidemiological context.

Situational diagnosis of the management of human resources in nursing in the countries/regions.

Characteristic management models of human resources planning in health and nursing in different countries and regions.

Successful experiences in human resources planning in nursing.

Effective strategies for management of labor disputes.

\section{Questions}

How can supply and demand for human resources in nursing be evaluated?

Which is the most effective strategy for adequate planning of human resources in nursing?

Which types of public policies are required for the planning, distribution, development, and assessment of human resources in nursing?

What is the impact of policies/standards on human resources for health and nursing that are currently in effect in the country?

How do policies on human resources for health, including civil service systems and collective bargaining agreements, affect the retention of nurses?

How do national and international policies/standards influence human resources in nursing in the countries of the region?

Which strategies and lines of action would foster the involvement of nursing professionals in the development of public health policies?

How do union policies influence human resources in nursing in the countries of the region?

How can a data acquisition system be set up or established for human resources planning in nursing?

Which organizational strategies can be conducted in situations of labor conflict within organizations?

Which models and instruments for management/planning of human resources in nursing are effective?

\subsection{Distribution}

\section{Topics}

Distribution of human resources in nursing according to social and health needs.

Impact of the nursing shortage.

Financial and regulatory policies for human resources in nursing.

Geographic and regulatory distribution of human resources in nursing.

Methods for analysis and/or evaluation of the nursing workforce.

\section{Questions}

To what degree do financial and non-financial incentives work to attract and retain skilled nursing workers in areas where services are limited?

Which is the optimal combination of financial, regulatory, and non-financial policies for the improvement of worker distribution and retention in nursing?

Which factors influence the supply, demand, and geographical and organizational distribution of human resources in nursing within the health workforce?

Which analytical and/or evaluation methods provide the most valid and reliable estimates on the scarcity or surplus of health professionals, based on the characteristics of the population, the burden of preventable diseases, hazards, and economic situation?

\subsection{Recruitment, retention, migration and regulation}

\section{Topics}

Recruitment, hiring, and retention of professionals to provide nursing care to vulnerable populations and in regions where health care resources are scarce.

Impact of the migration of nursing professionals.

Factors that facilitate or curtail the nurse migration process.

Recruitment and selection of human resources in nursing.

Models for regulation of human resources in nursing for Universal Health Coverage.

People management and employee retention in organizations.

\section{Questions}

Which is the cost-effectiveness of different funding strategies for recruitment and contracting of human resources in nursing within the context of universal access to health and universal health coverage?

What are the extent, causes, and effects of nurse migration in the country/region?

How does the migration of nursing professionals affect both countries of origin and of destination?

Which actions could mitigate nurse migration issues?

How do the components of compensation or insurance packages affect the recruitment and retention of nursing professionals?

How does double/triple/quadruple shift work impact nursing professionals?

What is the impact of different contract types on the workload or number of jobs of a nursing professional?

What are the existing models for regulation of nursing professionals in the countries and in the region?

Have existing regulatory models ensured the employment/incorporation of nursing professionals into the workforce in a manner consistent with their level of training, skills, and productivity?

Which are the strengths, weaknesses, opportunities and threats in models for regulation of the private sector? How can social justice in health be ensured in the regulation of double shift work (i.e., employment in both the public and the private healthcare networks)? 


\subsection{Education and professional competencies}

Comparative studies of the processes of regulation, education, and professionalization of human resources in nursing at the assistant, technician, undergraduate, specialization, master's, and doctoral levels.

Assessment and monitoring of professional competencies for higher- and mid-level nursing professionals. Identification of the personal characteristics and professional competencies of the leaders of nursing education programs.

Curriculum change and educational and technological innovations in human resources education in nursing. Development and assessment of educational innovations and technologies that improve the competencies of nurses, both those working in academia and those involved in patient care.

Impact of information and communication technologies on human resources education and nursing.

Assessment of innovations in the evidence-based teaching of health and nursing to support the acquisition of learning competencies in patient quality and safety.

Identification and assessment of the effectiveness of the new technologies in the teaching and decision-making abilities of nurses.

Educational models for education of human resources in nursing.

Analysis of curriculum models related to interprofessional practices.

Assessment of the effectiveness of partnerships between education and practice, with innovative teaching models, and their outcomes in terms of the quality of patient/family care.

Analysis of the effectiveness of various partnership models (instructors/staff members/students) in education and knowledge acquisition.

Identification and assessment of education models focused on patient-centered/family-centered care in a variety of clinical and community settings.

Evaluation of the effect of clinical residency programs in the professional performance of nurses.

Assessment of continuing education models and their effectiveness, efficiency, and effectiveness, taking into account their impact on the quality of healthcare.

Identification and assessment of strategies to address student attrition at the undergraduate and graduate levels.

Interprofessional education and management to promote work-related competencies in multidisciplinary teams.

\section{Questions}

Which assessment methods are most effective to produce valid and reliable measures of the abilities and competencies acquired by nursing students and professionals?

How do certification programs for health professionals and nurses affect the effectiveness, efficiency, and performance of public health strategies?

Which education and training models are most effective in improving the abilities and competencies (including cultural competencies) of nurses in primary care settings?

What are the impacts of the education, training, and competencies of public health nurses on the health-related needs of different countries?

What are the cost-effective interventions that improve the competencies of nursing instructors and students in the utilization and application of information and communication technologies?

What are the cost-effective interventions that improve pedagogical and methodological capacities and teaching/ learning styles during the education undergraduate and graduate nursing students in community environments, and what are the impacts of these experiences?

What is the impact of tutoring programs on the comprehensive education of nursing students?

What is the impact of including current and up-to-date content in the nursing curriculum?

Which are the available policy, cost, and deadline options that can increase the number of nurses?

Which competencies work in tandem to improve contemporary nursing care?

What is the number and profile of nursing graduates in each country?

How are the results of monitoring of new nursing graduates used in health policies, education, and professional practices?

Which strategies do countries implement to increase the presence of graduate or postgraduate professionals in the nursing workforce? Which of these strategies were most successful? Which strategies had little impact or poor costeffectiveness?

Which is the most current guiding strategy for human resources education in nursing in the context of systems based on an integrated and comprehensive approach to primary health care?

How can nurses be prepared and trained to become leaders of change and advance qualifications in the field of health?

What is the importance of permanent continuing education for nursing professionals?

Which are the most appropriate mechanisms to transform nursing human resources education and training curricula so that they will benefit the population?

Which mechanisms can increase the number of programs of human resources education in nursing?

What is the level of critical thinking ability of undergraduate-level nursing professionals in the countries of the Americas?

How are critical, analytical, and reflexive thinking imparted and demonstrated in the students of undergraduatelevel nursing programs?

Which mechanisms can contribute most effectively for groups of instructors to generate and implement innovations in the field of education in health?

Which strategies/approaches/content should be added to the curricula of nursing programs so that professionals will be trained to care for patients while taking into account cultural and socioeconomic diversity?

Which innovative teaching strategies are necessary for the training of nurses in research?

What is the contribution of the outputs of and processes generated by graduate programs to the quality of nursing care?

Figure 2 - Research topics/questions into subcategories of the category Policies and Education of Nursing Human Resources 


\section{STRUCTURE, ORGANIZATION, AND DYNAMICS OF HEALTH SYSTEMS AND SERVICES}

2.1 Models and structure of health care and nursing

Topics

Health systems, public policies, and nursing

Organization and management of health systems and services

Nursing interventions in individual and community health care

Scientific underpinnings for comprehensive nursing care

\section{Questions}

Which evidence-based, people-centered nursing interventions lead to high-quality outcomes?

What is the role and responsibility of nurses in the core competencies of the health system?

What is the extent of the involvement of nurses in the management and leadership of the health system and of the public health services?

Do analysis of the home environment, analysis of the work environment, and other socio-ecological assessments

improve the practices of nurses at the various levels of health care?

Which nursing competencies are most highly valued by the users of the healthcare network at its different levels of complexity?

Are public health practices in nursing based on a holistic approach, and, if so, has this facilitated societal recognition of nursing?

Which ethical, legal, and public policy-related aspects affect the place of nursing practice within the health system?

Which models are in place for nurses to communicate with health policy makers in their regions?

Which nursing interventions are effective in individual and collective health care?

How does the systematization of nursing care in primary care contribute to the achievement of universal access to health and universal health coverage?

\section{2 Healthcare work process and interprofessional collaboration}

\section{Topics}

Nurse-to-user ratio and its impact on individual and collective health outcomes.

Impact of multi- and interprofessional practice on patient/family/community care.

Development, assessment, and impact of teamwork on patients/families/communities.

\section{Questions}

What strategies are effective to improve the management and supervision of human resources in nursing in daily practice?

Which policies and incentives encourage interprofessional teamwork and cooperation?

Which models of care most efficaciously and effectively employ the skills/knowledge of nurses in primary care?

How does communication among healthcare and nursing team members affect the efficiency, effectiveness and efficacy of practice?

Which types of performance-based management systems can be implemented to optimize the performance of nursing teams?

Do existing health system structures enable the development of humane, comprehensive nursing practices?

Which are the challenges that nursing faces for implementation of a nursing care model at health facilities? Which strategies can be used to overcome such challenges?

How is teamwork organized in the context of primary health care? Which is the contribution of nursing?

2.3 Improvement of care quality, accreditation, and patient safety

\section{Topics}

Assessment of quality and humanization in nursing care.

Interventions to reduce or mitigate the errors and adverse events that occur in the health services.

Cost reductions as a result of patient safety improvements.

User satisfaction regarding the health services.

Patient safety in nursing care.

Organizational culture, patient safety, and nursing care.

Organizational climate and culture in healthcare.

Accreditation of health facilities and patient safety.

\section{Questions}

Do the work environment and the work process contribute to the occurrence of adverse events?

How can a culture of safety within the health services be supported?

How can non-financial incentives be used to optimize the efficiency and quality of care provided by nurses at all

levels of care?

Does the humanization of the care improve user satisfaction?

Does effective coordination of the care network improve user evaluations of the quality of nursing care?

Which elements related to nursing care contribute to user satisfaction regarding the quality of care provided?

Is user satisfaction related to the quality of nursing care?

How can databases be used to improve the quality and safety of nursing care?

Which indicators of quality of nursing care are most adequate/appropriate in different services and health contexts? Are effectively implemented continuing education policies associated with a reduction in institutional adverse event rates and with the quality of nursing care?

\subsection{Occupational health}

Topics

Prevalence and incidence of risk exposure, occupational diseases, and occupational accidents.

Status of the implementation of standards and organization of services for the management of occupational health and safety. 
Strategies that minimize occupational adverse events.

Effectiveness the interventions to reduce work-related stress and stressors among health and nursing professionals.

Assessment of intervention strategies to improve the health and safety of nursing professionals.

Strategies to increase the adherence of health and nursing professionals to personal protective equipment use.

Impact of occupational health nursing interventions on workers' compensation.

Impact of violence on the work, satisfaction, and retention of nursing professionals.

Situational diagnosis of work-related suffering and pleasure and its impact on the quality of nursing care.

Assessment of the impact of health and nursing professionals' health conditions on absenteeism rates and quality of nursing care.

Gender and nursing work.

\section{Questions}

What are the prevalence and incidence rates of risk exposure, occupational diseases, and occupational accidents in each national context and in Latin America as a whole?

Which strategies have an impact on the reduction of work-related adverse events?

Which strategies are effective and efficacious in boosting the motivation of health and nursing professionals to wear personal protective equipment?

How can nursing interventions in occupational health reduce workers' claims and workers' compensation?

What is the impact of working conditions on the health of nursing professionals?

What is the relationship between workers' health conditions and absenteeism rates and quality of nursing care?

Which factors act as facilitators and barriers to the achievement of adequate working conditions for health and

nursing professionals in each national context and in Latin America as a whole?

How can the work-related satisfaction of health and nursing teams be evaluated?

Which cost-effective interventions increase the level of work-related satisfaction among health and nursing professionals?

Which strategies can ensure the safety of nursing professionals exposed to highly communicable diseases?

Do health facilities provide personal protective equipment in sufficient quantities, of sufficient quality, and in a timely fashion to health and nursing professionals?

What is the impact of organizational culture on the occupational health of health and nursing professionals?

Which are the implications of gender to management and occupational safety in health and nursing?

\subsection{Professional performance}

\section{Topics}

Effectiveness of nursing professional performance at the different levels of health care.

Cost-effectiveness of nursing care.

Methods and instruments for measurement of practice quality in accordance with professional competencies.

Ethical aspects related to professional performance.

\section{Questions}

What is the cost-effectiveness of employing public health nurses as part of multidisciplinary teams?

What are the problem-solving and coordinating abilities of nursing professionals at the various levels of care?

What is the cost-effectiveness of employing public health nurses to coordinate epidemiological surveillance (e.g., to reduce the incidence of hospital-acquired infections)?

How is the performance of public health nurses in terms of fostering healthy communities evaluated at the local, subnational, national, and international levels?

What is needed to implement humanized, comprehensive nursing practice at health facilities?

What other professional competencies do nursing professionals need to obtain effective results from their work in interdisciplinary teams?

\subsection{Cost-effectiveness}

\section{Topics}

Health management systems.

Health services funding.

Cost-effectiveness in multidisciplinary and interdisciplinary health care.

\section{Questions}

How can financial and non-financial incentives be used to optimize the efficiency and quality of nursing care? Which are the conditions, regulations, and financial and non-financial resources needed to efficiently implement changes in the tasks of health and nursing professionals?

What is the cost-effectiveness of the different mechanisms used to expand programs for training human resources in nursing before these professionals are hired?

What management models can/should be implemented to increase the value afforded to the training/qualification level of nursing professionals, with fair compensation adequate to the level of responsibility of each team member? What is the effectiveness of implementing incentives and pay-for-performance initiatives for nursing professionals? What is the effectiveness of the different types of management systems that contribute to the performance of nursing professionals?

What is the effectiveness of relicensure or recertification to improve the performance of nursing professionals? What is the effectiveness and cost-effectiveness of patient and user feedback mechanisms to improve the performance of nursing professionals?

How does turnover of nursing personnel influence the efficacy, efficiency and effectiveness of public health strategies provided at the local, subnational, and national levels?

What are the benefits, costs, and return on investment at the various levels of teaching and training in public health nursing?

What are the costs and benefits of nursing certification in terms of the quality of patient care? 
Do the results of professional certification translate into improvement of professional nursing practices and an improvement in patient/family/community care?

What is the effectiveness and/or cost-effectiveness of the implementation of incentives to ensure that the number of nursing professionals is sufficient for each country?

How can the impact of the financial constraints of health systems on training and human resources development in nursing be assessed?

Figure - 3 Research topics/questions into subcategories of the category Structure, Organization, and Dynamics of Health Systems and Services

\section{SCIENCE, TECHNOLOGY, INNOVATION, AND INFORMATION SYSTEMS IN PUBLIC HEALTH Topics \\ Strategies to increase public and private funding in order to promote nursing research. \\ Strategies for institutional changes that facilitate the translation of scientific evidence into practice.}

Measurement of cost-effective technologies, such as online access, simulation, telehealth, and mobile health, used to expand the capacity of nursing education.

Technologies, research networks, and human resources support that allow nurses devoted to patient care to conduct more scientific research.

Assessment of user satisfaction with the health system.

Effective to incorporate participatory mechanisms and user/community perspectives into the decision-making process in health and nursing.

Management practices that promote the construction of environments conducive to innovation in public health.

\section{Questions}

Which factors act as facilitators and barriers to the use of evidence generated by nursing research?

How can health facilities successfully implement evidence-based decision-making?

How can the access to and utilization of evidence-based information, data, and practices influence nursing practice?

How can nursing curricula focused on evidence-based practice be designed and operationalized?

Does providing research training to nurses influence the development of health research?

Which barriers prevent nurses from applying scientific evidence to their work?

Which barriers prevent nurses from having access to scientific evidence?

How can the use of information technologies as a part of daily nursing practice be legitimized?

Which institutional policy measures are most effective for the production of nursing knowledge and technology in primary health care settings?

Figure 4 - Research topics/questions of the category Science, Technology, Innovation, and Information Systems in Public Health

\section{FINANCING OF HEALTH SYSTEMS AND SERVICES \\ Topics}

Impacts of funding on nursing practice in primary health care.

Funding and models of health care and nursing.

Strategies for investment, indicators, and human development.

\section{Questions}

How does the funding process influence the effective implementation of nursing strategies in public health at the local, national, international, and global level?

How do the effects of the economic recession influence public health nursing strategies?

What is the impact of public health nursing investment strategies on indicators of human development?

How can resources and strategies for public health nursing be mobilized and facilitated?

What are the strengths and weaknesses of current resource mobilization strategies for public health nursing? Which incentive mechanisms can be implemented to disseminate nurse-led models of care?

Figure 5 - Research topics/questions of the category Financing of Health Systems and Services 


\section{HEALTH POLICIES, GOVERNANCE, AND SOCIAL CONTROL}

Topics

5.1 Health policies and management of human resources, healthcare services, and nursing.

5.2 Knowledge production and decision-making in health care and nursing.

5.3 Impact of nursing knowledge production on health policy development.

5.4 Impact of nursing interventions on the improvement of population-wide health conditions.

5.5 Nursing and social control.

5.6 Types/Models of nursing governance and their impact on nursing practice and health care.

Questions

5.7 What is the role of management in the delivery of nursing services?

5.8 What is the role of management in the performance of nursing professionals in the public health sector?

5.9 How can partnerships between institutions, policies, and research be constructed in nursing, and how are such partnerships carried out?

5.10 What are the determining factors of the efficacy and effectiveness of nursing organizations in the regulation of nursing practice?

5.11 Which mechanisms and strategies are used by nurses to ensure the effective participation of individuals and of society at large in addressing population health issues?

5.12 How can the effectiveness of nursing interventions in improving the health status of the population be demonstrated?

5.13 Which strategies are used to demonstrate the contribution of nursing to patient, family, and community care at a societal level, locally, nationwide, and internationally?

5.14 Is nursing research used for decision making in public health policies?

5.15 To what extent does nursing research contribute to addressing the most prevalent health problems of each country/region, and what is the impact of nursing research on these problems?

5.16 Which criteria are used to allocate financial resources to human resources education in nursing and to the conduction of research to respond to the demand for care?

5.17 How is research linked to innovation in nursing, taking into account the priorities for social development and public health?

5.18 How does nursing contribute to knowledge of the social determinants of health?

5.19 How does the social control of users over services influence decision-making in health care and nursing practices?

5.20 Which models of governance (shared, clinical, public, etc.,) have been applied to the field of nursing? How have nurses been applying these governance models in different primary health care settings?

Figure 6 - Research topics/questions of the category Health Policies, Governance, and Social Control

\section{SOCIAL STUDIES IN THE HEALTH FIELD}

\subsection{Sociocultural and economic analysis of health and nursing professions}

\section{Topics}

Processes of constitution of a professional identity for nurses and other nursing professionals: strengths and weaknesses.

Diagnosis of the societal view of nurses and other nursing professionals, their social representation, and obstacles posed by users and health teams.

Social representation of nurses and nursing.

Social conditions and professional performance of nursing.

\section{Questions}

Which tensions have been identified in the process of constitution of the health and nursing professions? What is the social representation of nursing professionals among the population and other health professionals? How does the societal view of nurses influence the performance of nursing professionals?

Which social conditions influence the performance of the nursing profession?

Which social factors determine the performance of nursing professionals?

Do health systems facilitate a professional nursing practice integrated into the context and social reality in which people live?

How is nursing professionals' quality of life related to social and labor policies in each country?

To what extent does society recognize the work of nurses and other nursing professionals?

Which strategies can be implemented to promote a good image of the nursing profession/of nursing professionals? 6.2 Historical analysis of nursing practice

\section{Topics}

Historical evolution of nursing worldwide and in the Region of the Americas.

Globalization and nursing.

Impact of information and communication technologies on nursing care.

Changes in health care and knowledge generation in nursing.

Nursing, society, and public policy. 


\section{Questions}

How does the globalized scenario impact the performance of nursing practice?

What/How has been the historical evolution of nursing practice?

Which historical patterns have been identified in the development of the social practice of nursing?

What has been the historical participation of nurses in the decision-making process and in public policy

development?

From a historical standpoint, how have transformations in nursing care been occurring, and how do these transformations relate to advances in nursing knowledge?

From a historical standpoint, how have transformations in nursing care been occurring, and how do these transformations relate to improvement in the outcomes of nursing care and of healthcare as a whole?

How can the professional identity of nurses be fostered so they will understand their role of co-responsibility in public policy-making, health policy-making, and in the global status of nursing? (i.e., their political role/ knowledge?)

\subsection{Marketing and health consumers}

\section{Topics}

The media and health.

The media and healthy lifestyles.

Role of nursing organizations in improving the visibility of nursing.

Strategies for use of marketing in improving the societal view of nursing.

\section{Questions}

What is the influence of social media on the search for healthcare and nursing care?

What are the best marketing strategies for the adequate utilization of health and nursing services by health consumers?

How does marketing influence the lifestyle of the population with regard to health?

How are healthcare and nursing care perceived by the community at the various levels of care?

Which aspects are employed by users/the community in evaluating the work of nursing professionals and the quality of nursing care?

What is the social analysis of health and nursing professionals in the work environment?

Is historical analysis of health and nursing practice currently relevant?

What strategies can nursing organizations (associations, societies, boards) use to promote the nursing profession among society?

\subsection{Societal image of nursing \\ Topics}

Societal image of nursing professionals.

Assessment of media influence on the image of health care: progress and challenges.

Assessment of media influence on the image of nurses and other nursing professionals: progress and challenges.

\section{Questions}

On which axes is the societal image of nursing and nurses based?

How do the users of the health system (population and professionals) perceive the image of nursing/nurses?

Which factors could modify the societal image of nursing/nurses?

Does the societal image of nursing professionals have a negative impact on the compensation that nursing

professionals receive as compared with other health occupations?

How can the societal image of nursing/nurses be enhanced?

Does improvement of the societal image of nurses improve their self-image, their self-efficiency, and the quality of healthcare?

Currently, which is the social and professional identity of nursing professionals?

Currently, how is the media portraying nurses and other nursing professionals in television shows and other media? Is the image of nurses and other nursing professionals portrayed in television or elsewhere in the media consistent with the reality of these professionals?

How can the media be monitored and collaborated with so as to improve representations of nurses and nursing professionals?

Which strategies can be implemented to foster a wholesome image of the nursing profession and its professionals? How have global and country-specific health contexts and sociocultural contexts impacted the image of nursing throughout history?

How has the image of nursing developed as a function of global and country-specific contexts?

How does the image and/or professional identity of nursing relate to the current context in the Americas and globally?

Figure 7 - Research topics/questions into subcategories of the category Social Studies in the Health Field

\section{Discussion}

The 2013 World Health Report "Research for universal health coverage", proposed that research for universal health coverage be tailored to the broader context of development research. "Research will play a role not only in meeting the Millennium Development Goals (MDGs) but also in supporting the post-2015 
development agenda. [...] Because many more questions can be asked than answered, it is vital to set priorities for investigation"(14).

Human Resources for Health are one of the major barriers for Universal Health expansion in developing countries where they are often insufficient in numbers and in ditribution. In order to expand effective and equitable health coverage and guarantee access, the countries in the Latin American region should improve human resource capacity, skill mix, availability and distribution (15).

In Latin America, 11 countries face a severe shortage of health professionals (less than 25/10,000 inhabitants $)^{(5)}$, which has proven to be a major challenge in the region and can be illustrated by the great number of study topics/questions that arose during the consensus process. From the final research list, 30\% (83) of the total research topics/questions are related to category 1: Policies and education of nursing human resources.

Furthermore, the Resolution previously mentioned urges PAHO's Member States to "improve human resource capacity at the first level of care, increasing employment opportunities with attractive labor conditions and incentives, particularly in underserved areas; consolidate collaborative multidisciplinary health teams; ensure that these teams have access to health information and telehealth services (including telemedicine); and introduce new professional and technical profiles and strengthen existing ones, coherent with the model of care to be implemented to achieve universal access."(1)

Another major issue is the structure, organization and dynamics of health systems and services in Latin America. Since Universal Health demands an expansion of health services where quality should be imperative, this requires mechanisms that can effectively monitor quality and safety of care, both technically and in the interpersonal dimension ${ }^{(15)}$. The category relating to this area represented $34 \%$ of the total research topics/ questions, demonstrating some concern by the experts in regards to health systems' organization and structure.

The forth category, related to financing issues another controversial aspect, has only nine research questions/topics, a number that decreased significantly throughout the consensus process. This demonstrates that nurses are still not involved enough in the development of health policies, even though efficient financing mechanisms are crucial to ensure Universal Health(14-15).
Moreover, while health systems financing is deemed as important for achieving the Millennium Development Goals, funding for this research field is often not aligned with national priorities ${ }^{(10)}$.

Regarding methodological aspects, one of the strengths of this study was the broad range of participants involved, including representation by nursing researchers, faculty and practitioners, deans, representatives of professional entities, regulatory bodies and ministries of health, public health leaders, nursing journal and nursing network coordinators from across Latin America. Another study on research priorities setting in Latin America highlights the importance of the participation of diverse key actors in order to avoid bias and to balance research interests ${ }^{(16)}$.

Although some of the documents selected during the systematic review stage were related to the United States context, the participation of experts solely from Latin America, and the criteria established for ranking or modifying the questions shaped the priority setting process to the Latin American region with a focus on the concepts of Universal Health.

Participants used a 3-point Likert scale over a 5-point scale because other studies have shown that allowing experts multiple options limited the identification of priority interventions ${ }^{(17)}$.

Lastly, in spite of the great number of topics and questions for a priority list, items were identified and agreed upon consensus of at least 159 people representing 14 countries; moreover, one should consider that, using this document as a basis, each country may select the items deemed as priority within its own contextual needs. The autonomy of each country concerning ways to achieve $\mathrm{UAH}$ and $\mathrm{UHC}$ needs to be ratified due to each member state's unique historical, cultural, political and economic characteristics ${ }^{(18)}$.

The identification of nursing research priorities should be a dynamic and fluid process, which will require regular updates, reviews, and consultations involving a variety of actors: governments, academic and research institutions, research support agencies, researchers, professionals, and practitioners.

\section{Conclusion}

It is possible to achieve consensus through a highly participative method, including a broad range of participants' diverse contexts, although to be effective this process may demand considerable time and commitment from its stakeholders. 
Moreover, for the reasons mentioned above, this list will be suitable for any country in the region, allowing them to set their own research priorities adapted to their contextual needs, while aiming to advance Universal Access to Health and Universal Health Coverage.

The findings of this study are expected to serve as guidance and support for the of nursing research on health systems and services across the region. Additionally, not only are researchers encouraged to consult this list of priorities, leaders of ministries of health, public health and research funding agencies can also use this list to help inform research-funding decision-making.

\section{Disclaimer}

The opinions expressed herein are those of the authors and do not necessarily reflect the views of the Pan American Health Organization.

\section{Acknowledgments}

Our special gratitude to all nursing faculty, experts and practitioners, public health leaders, ministry of health officials, and PAHO's staff who took part in the consultations undertaken for the development of this list of nursing research priorities.

The authors want to express their gratitude to all professionals from the many countries involved in the revision of the research topics.

\section{References}

1. Pan American Health Organization. Strategy for universal access to health and universal health coverage. Proceedings of the 53rd Directing Council (CD53/5, Rev. 2) [Internet] Washington DC; October 2014. [Acessed 10 mai 2015]. Retrieved from: http://bit. ly/1DuHUIk

2. World Health Organization. Positioning Health in the Post-2015 Development Agenda. WHO discussion paper. 2012 [Internet]. [Acessed 14 may 2015]. Retrieved from: http://www.who.int/topics/millennium_ development_goals/post2015/WHOdiscussionpaper_ October2012.pdf

3. Andrade LOM, Pellegrini Filho A, Solar O, Rígoli F, Salazar LM, Serrate PCF. Social determinants of health, universal health coverage, and sustainable development: case studies from Latin American countries. Lancet. 2015;385:1343-51.
4. World Health Organization. Nursing and midwifery services: strategic directions 2011- 2015 [Internet]. Geneva: WHO; 2010. [Acessed 12 mar 2015]. Retrieved from: www.who.int/hrh/nursing_midwifery/en/

5. Cassiani SHB. Strategy for universal access to health and universal health coverage and the contribution of the International Nursing Networks. Rev. Latino-Am. Enfermagem. 2014; 22(6):891-2.

6. Yamin $A E$, Frisancho A. Human-rights-based approaches to health in Latin America. Lancet. 2015;385:e26-e29.

7. Marziale MHP. Scientific production in Brazilian nursing: the search for international impact. Rev. LatinoAm. Enfermagem. 2005;13(3):287-8.

8. House J, Parmar J, Reveiz L, Cassiani S. Health literature authored by nurses within the LAC region: a cross sectional study. Rev Panam Salud Publica. [In press].

9. Mendoza-Parra S, Paravic-Klijn T, Muñoz-Muñoz $A M$, Barriga OA, Jiménez-Contreras E. Visibility of Latin American nursing research (1959-2005). J Nurs Scholarsh. 2009;41(1): 54-63.

10. Ranson K, Law TJ, Bennett S. Establishing health systems financing research priorities in developing countries using a participatory methodology. Socl Sci Med. 2010;70:1933-42.

11. Maceira D, Paraje G, Aramayo F, Duarte Masi S, Sánchez D. Financiamiento público de la investigación en salud en cinco países de América Latina. Rev Panam Salud Publica. 2010; 27(6):442-51.

12. Campbell SM, Cantrill JA. Consensus methods in prescribing research. J Clin Pharm Therapeut. 2001;26:5-14.

13. Bassalobre Garcia A, Cassiani SHB, Reveiz L. A systematic review of nursing research priorities on health system and services in the Americas. Rev Panam Salud Publica. 2015; 37(3):162-71.

14. World Health Organization. The World Health Report: research for universal health coverage. Geneva: WHO; 2013.

15. Frenk J. Leading the way towards universal health coverage: a call to action. Lancet. [Internet];2015 [Acessed 10 mai 2015];385:1352-8. Retrieved from: http://www.sciencedirect.com/science/article/pii/ S0140673614614677.

16. Becerra-Posada F, Salgado de Snyder N, Cuervo LG, Montorzi G. Agendas de investigación priorizadas: un recurso estratégico para la salud en América latina. Rev Panam Salud Publica. 2014;36(6):361-7. 
17. Caminal J, Starfield B, Sanchez E, Morales $M$. The role of primary care in preventing ambulatory care sensitive conditions. European J Public Health. $2004 ; 14(3): 246-25$.

18. Etienne CF. Achieving universal health coverage is a moral imperative. Lancet. 2015;385: 1271-73. 